\title{
PERTUMBUHAN ANAK SEKOLAH DASAR YANG MENGALAMI STUNTING UMUR 0-23 BULAN
}

\section{GROWTH OF ELEMENTARY SCHOOL CHILDREN WHO HAVE STUNTING IN AGES 0-23 MONTHS}

\author{
Samuel Samuel, ${ }^{1 *}$ Asep Riyana ${ }^{2}$ \\ ${ }^{1} J u r u s a n$ Gizi Poltekkes Kemenkes Tasikmalaya \\ ${ }^{2} J u r u s a n$ Keperawatan Poltekkes Kemenkes Tasikmalaya \\ E-mail :' wairisal29@yahoo.co.id, ${ }^{2}$ banisulaeman@gmail.com
}

\begin{abstract}
ABSTRAK
Penelitian ini bertujuan menganalisis pertumbuhan anak sekolah dasar yang mengalami stunting, umur 0-23 bulan. Desain penelitian cross sectional, longitudinal, data awal dikumpulkan pada tahun 2009, data kedua dikumpulkan pada tahun 2018, dengan jumlah sampel 91 anak yang terdiri dari 34 anak yang mengalami stunting umur 0-23 bulan dan 57 anak yang tidak mengalami stunting umur 0-23 bulan. Data yang dikumpulkan berupa panjang badan saat usia kurang dari 2 tahun dan data tinggi badan saat usia sekolah. Uji statistic menggunakan Chi-square. Hasil penelitian menunjukkan ada perbedaan proporsi gangguan pertumbuhan antara anak sekolah dasar yang memiliki riwayat stunting dengan yang tidak memiliki riwayat stunting $(p<0,05)$. Nilai Prevalensi Rasio (PR) 2,3 (95\% Cl=1,0-5,2), yang berarti stunting yang terjadi pada usia di bawah dua tahun merupakan faktor risiko gangguan pertumbuhan anak sekolah dasar.
\end{abstract}

\section{Kata kunci : Pertumbuhan, Anak, Sekolah Dasar, Stunting.}

\section{ABSTRACT}

This study aims to analyze the growth of elementary school children who experience stunting, at the age of 0-23 months. The study design was cross sectional, longitudinal, preliminary data collected in 2009, the second data was collected in 2018, with a total sample of 91 children consisting of 34 children who were stunted at 0-23 months and 57 children who did not experience stunting at age 0-23 months. Data collected in the form of the body length at less than 2 years of age and height data at school age. Statistical test using Chi-square. The results showed there were differences in the proportion of growth disorders between elementary school children who had a history of stunting and those who had no history of stunting $(p<0.05)$. Prevalence Ratio (PR) $2.3(95 \% \mathrm{Cl}=$ $1.0-5.2)$, which means stunting that occurs under the age of two years is a risk factor for growth disorders in primary school children.

Keywords: Growth, Children, Elementary School, Stunting. 


\section{PENDAHULUAN}

Permasalahan stunting yang terjadi umur kurang dari dua tahun (baduta), sangat menentukan tumbuh kembang selanjutnya.,2 Periode ini sistem saraf pusat berkembang dengan sangat cepat. ${ }^{3}$ Anak baduta yang memiliki status gizi baik, akan mengalami perkembangan sel otak mencapai $80 \%$ dari perkembangan otak dewasa. Selain itu pemenuhan kecukupan zat gizi sangat penting untuk memaksimalkan pertumbuhan dan perkembangan otak anak. ${ }^{5}$

Kekurangan zat gizi akan menyebabkan gangguan pertumbuhan tinggi badan. ${ }^{6}$ Stunting merupakan gangguan pertumbuhan tinggi badan. ${ }^{7}$ Hasil Riset Kesehatan Dasar (RISKESDAS) 2018 di Indonesia menyatakan prevalensi stunting yang terjadi pada usia 023 bulan sebesar $29,9 \%$ dan pada kelompok umur (5-12 Tahun) sebesar 23,6\%.

Gangguan pertumbuhan tinggi badan dapat diprediksi dari pertumbuhan pada tahuntahun pertama kehidupan. ${ }^{9}$ Anak yang mengalami gagal tumbuh pada usia balita akan menjadi remaja atau dewasa pendek, dan jika remaja/dewasa ini hamil akan melahirkan lagi bayi dengan berat badan rendah. ${ }^{10}$ Selain itu peranan intervensi gizi akan berdampak pada pertumbuhan linear setelah umur dua tahun, ${ }^{11}$ Masih tingginya prevalensi stunting pada anak usia $<2$ tahun, dan juga diikuti dengan tingginya prevalensi stunting pada anak usia sekolah dasar, dan dengan dasar teori yang menyatakan bahwa gangguan pertumbuhan tinggi badan dapat diprediksi dari pertumbuhan tahun-tahun sebelumnya, sehingga kami ingin mengkaji apakah stunting di usia kurang dari dua tahun sebagai salah-satu faktor resiko gangguan pertumbuhan pada anak sekolah dasar.

\section{METODE PENELITIAN}

Penelitian ini telah mendapat persetujuan dari Komisi Etik Penelitian Kesehatan (KEPK)
Politeknik Kesehatan Kemenkes Tasikmalaya No.2018/KEPK/ PE/VII/0007. Desain penelitian cross sectional longitudinal. Data awal dikumpulkan pada tahun 2009 saat anak masih berusia antara 0-23 bulan dan data pertumbuhan anak sekolah dikumpulkan pada tahun 2018. Responden pada penelitian ini adalah anak sekolah dasar kelas 3 sampai dengan kelas 6 , usia 10-11 tahun berjumlah 91 siswa.

Tempat penelitian di Kecamatan Lemahabang Kabupaten Cirebon yang merupakan salah satu wilayah prioritas penanganan stunting nasional. ${ }^{12}$ Teknik penarikan sampel untuk data awal dilakukan secara purposive random sampling dimana semua anak usia 0-23 bulan dilakukan pengukuran panjang badan menggunakan infantometer dengan ketelitian $0,1 \mathrm{~cm}$. Data kemudian diolah menggunakan software WHO- Anthro, berdasarkan indeks Panjang Badan menurut Umur (PB/U) untuk menentukan status stunting dan normal. Kemudian untuk data pertumbuhan anak sekolah, tahap pertama dilakukan penentuan desa sasaran berdasarkan prevalensi stunting tertinggi pada tahun 2009 atau berdasarkan data awal, dan terpilih sebanyak 4 desa sebagai tempat penelitian. Sampel dipilih secara systematic random sampling berdasarkan daftar list yang sudah dibuat.

Data yang dikumpulkan berupa identitas anak, yaitu nama, alamat, tanggal lahir, tanggal pengukuran, tinggi badan siswa menggunakan stadiometer dengan ketelitian $0,1 \mathrm{~cm}$ dan umur. Data diolah menggunakan program software dan WHO-AnthroPlus. untuk mengidentifikasi berdasarkan indeks Tinggi Badan menurut Umur (TB/U). Jika hasilnya kurang dari -2 z score standar baku WHO dikategorikan stunting atau gangguan pertumbuhan. ${ }^{13}$ 
HASIL

Tabel 1. Data karakteristik responden berupa jenis kelamin, dan umur. Hasil penelitian ini menunjukkan responden laki-laki lebih banyak 9,8\% dari responden perempuan. Berdasarkan sebaran umur responden terbanyak berusia 10 dan 11 tahun dibandingkan dengan umur 8 dan 12 tahun.

Tabel 1. Karakteristik Responden Berdasarkan Jenis Kelamin, dan Umur

\begin{tabular}{lll}
\hline Variabel & $\mathrm{n}$ & $\%$ \\
\hline Jenis kelamin & & \\
Laki-laki & 50 & 54,9 \\
Perempuan & 41 & 45,1 \\
\hline Umur & & \\
9 tahun & 8 & 8,8 \\
10 tahun & 43 & 47,3 \\
11 tahun & 38 & 41,8 \\
12 tahun & 2 & 2,2 \\
\hline
\end{tabular}

Tabel 2. Data riwayat stunting saat anak berumur 0-23 dan gangguan pertumbuhan diusia sekolah. Proporsi kejadian stunting pada laki-laki saat berumur 0-23 bulan, sebesar 40,0\% kemudian pada usia sekolah berkurang sebesar $22 \%$ dan proporsi kejadian stunting pada anak perempuan saat umur 0-23 bulan sebesar 34,1\% dan gangguan pertumbuhan (pendek) pada usia sekolah sebesar $24,4 \%$ atau berkurang sebesar $9,7 \%$. Penurunan terbanyak terjadi pada anak laki-laki dibandingkan dengan anak perempuan. Artinya proporsi tumbuh kejar laki-laki lebih banyak dari anak perempuan

Tabel 3. Resiko gangguan pertumbuhan pada anak sekolah dasar yang memiliki riwayat stunting di umur $0-23$ bulan. Penelitian ini menunjukkan sebanyak $32,4 \%$ anak stunting pada umur 0-23 bulan mengalami gangguan pertumbuhan sekolah dasar, dan sebanyak 14,0\% anak yang tidak memiliki riwayat stunting mengalami gangguan pertumbuhan pada usia sekolah. Hasil uji statistik menunjukkan ada perbedaan proporsi antara anak sekolah dasar yang memiliki riwayat stunting, dengan anak sekolah dasar yang tidak memiliki riwayat stunting $\mathrm{p}<0,05)$. Berdasarkan hasil hitung PR; 2,3 (95\% Cl= 1,0-5,2), dapat diartikan bahwa stunting yang terjadi pada usia 0-23 bulan merupakan faktor risiko gangguan pertumbuhan pada anak sekolah, atau anak dengan riwayat stunting berisiko mengalami gangguan pertumbuhan 2,3 kali lebih besar dari anak yang tidak memiliki riwayat stunting.

\section{Tabel 2. Proporsi Riwayat Stunting Umur 0-23 Bulan dan Pertumbuhan anak Sekolah Dasar}

\begin{tabular}{|c|c|c|c|c|}
\hline \multirow{3}{*}{ Pertumbuhan } & \multicolumn{4}{|c|}{ Jenis Kelamin } \\
\hline & \multicolumn{2}{|c|}{ Laki-laki } & \multicolumn{2}{|c|}{ Perempuan } \\
\hline & $\mathrm{n}$ & $\%$ & $\mathrm{n}$ & $\%$ \\
\hline \multicolumn{5}{|c|}{$\begin{array}{l}\text { Riwayat Stunting } \\
\text { Umur 0-23 Bulan }\end{array}$} \\
\hline Stunting & 20 & 40,0 & 14 & 34,1 \\
\hline Normal & 30 & 60,0 & 27 & 65,9 \\
\hline \multicolumn{5}{|c|}{$\begin{array}{ll}\text { Usia } & \text { Sekolah } \\
\text { Dasar } & \end{array}$} \\
\hline Pendek & 9 & 18,0 & 10 & 24,4 \\
\hline Normal & 41 & 82,0 & 31 & 75,6 \\
\hline
\end{tabular}

Tabel 3. Risiko Gangguan Pertumbuhan pada Anak Sekolah Dasar yang Memiliki Riwayat Stunting di Umur 0-23 Bulan.

\begin{tabular}{|c|c|c|c|c|}
\hline \multirow{3}{*}{$\begin{array}{l}\text { Riwayat } \\
\text { Stunting } \\
\text { Umur } \\
(0-23) \\
\text { bln. }\end{array}$} & \multicolumn{2}{|c|}{$\begin{array}{c}\text { Gangguan } \\
\text { Pertumbuhan }\end{array}$} & \multirow{3}{*}{$p$} & \multirow{3}{*}{$\begin{array}{c}\text { PR } \\
(95 \% \\
\mathrm{Cl})\end{array}$} \\
\hline & $\mathrm{Ya}$ & Tidak & & \\
\hline & $\mathrm{n} \quad(\%)$ & n $\quad(\%)$ & & \\
\hline $\mathrm{Ya}$ & $11(32,4)$ & $23(67,6)$ & & 2,3 \\
\hline Tidak & $8(14,0)$ & $49(86,0)$ & $0,03^{*}$ & $\begin{array}{l}(1,0- \\
5,2)\end{array}$ \\
\hline
\end{tabular}

Keterangan: Uji Chi square, ${ }^{*}$ Signifikan $p<0,05$ 


\section{PEMBAHASAN}

Stunting atau gangguan pertumbuhan adalah gejala yang paling sering digunakan sebagai proksi kekurangan gizi kronis. ${ }^{14}$ Dampak yang ditimbulkan dari kekurangan gizi kronis yaitu terhambatnya pertumbuhan linier, dimana tubuh merespon kekurangan gizi tersebut dengan pemanfaatan zat gizi yang minimal sehingga terjadi perubahan patologis yang berdampak pada gangguan pertumbuhan. Proses ini dapat berlangsung selama periode pertumbuhan manusia, mulai dari masa konsepsi, masa balita, anak dan remaja. $^{15}$

Tinggi badan merupakan salah-satu ukuran antropometri yang sangat penting untuk mengetahui proses pertumbuhan, ukuran tinggi badan akan terus meningkat pada masa bayi kemudian kembali pesat pada masa remaja dan lambat kemudian berhenti pada usia $18-20$ tahun. ${ }^{16}$

Hasil penelitian ini menunjukkan bahwa pada umur 0-23 bulan, proporsi kejadian stunting pada laki-laki sebesar 40,0\% kemudian berkurang sebesar $22 \%$ saat usia sekolah dan untuk perempuan pada umur 0-23 bulan sebesar $34,1 \%$ dan berkurang sebesar $9,7 \%$ pada usia sekolah. Artinya proporsi tumbuh kejar laki-laki lebih banyak dari anak perempuan. Sejalan dengan penelitian di Bangladesh 2016, yang menyatakan bahwa pada umur 6 dan 12 bulan anak laki-laki memiliki prevalensi stunting yang lebih tinggi dibandingkan anak perempuan, kemudian pada umur 10 tahun prevalensi stunting pada perempuan lebih tinggi $(32,4 \%)$ daripada anak laki-laki $26,2 \%,{ }^{17}$ dimana pada umur 12 tahun laki-laki mengalami pertumbuhan tinggi badan yang pesat, dari anak perempuan. sehingga rata-rata tinggi badan pada laki-laki tampak berbeda dari perempuan. ${ }^{18}$

Penelitian ini menunjukkan bahwa anak yang mengalami stunting pada usia 0-23 bulan, $32,4 \%$ mengalami gangguan pertumbuhan umur sekolah dasar, dan sebanyak 14,0\% anak yang tidak memiliki riwayat stunting umur 0-23 bulan mengalami gangguan pertumbuhan pada usia sekolah. Hasil uji Chi square menunjukkan bahwa stunting yang terjadi pada usia 0-23 bulan merupakan faktor risiko gangguan pertumbuhan anak, atau anak dengan riwayat stunting berisiko 2,3 kali lebih besar mengalami gangguan pertumbuhan.

Kegagalan pertumbuhan disebabkan banyak faktor diantaranya konsumsi zat gizi yang kurang dari kebutuhan dan berdampak pada tidak optimalnya pertumbuhan linier. Faktor lain seperti sosial ekonomi, pendidikan orang tua dan pendapatan keluarga mempengaruhi terhadap kualitas dan kuantitas asupan gizi serta meningkatnya insiden penyakit. $^{19}$ Penelitian, mengungkapkan bahwa masalah kekurangan gizi dan infeksi parasit banyak terjadi pada anak sekolah. ${ }^{20}$ Kebiasaan mencuci tangan merupakan faktor dominan risiko infeksi parasit, anak yang kadang kadang mencuci tangan berisiko 5,5 kali terinfeksi parasit dibandingkan dengan anak yang selalu mencuci tangan. ${ }^{21}$ Dampak lain yang ditimbulkan dari gangguan pertumbuhan pada anak risiko kelebihan berat badan. Hasil penelitian menyebutkan ada hubungan yang signifikan kejadian stunting dengan kelebihan berat badan. ${ }^{22}$

\section{SIMPULAN}

Proses tumbuh kejar laki-laki lebih banyak terjadi dari anak perempuan, dan stunting yang terjadi pada usia di bawah dua tahun merupakan salah satu faktor risiko gangguan pertumbuhan anak sekolah dasar.

\section{DAFTAR PUSTAKA}

1. Escamilla RP. Post-1000 days growth trajectories and child cognitive development in low- and middle- 
income countries. Am J Clin Nutr. 2013;98:1375-1376.

2. Strang B, Eardley K, Schulz S,Benedict M, Dority D, Rees $P$, Thomas et al. The best start saving children's lives in their first thousand days, This group is meeting to discuss nutrition for children and pregnant mothers. Bolivia September 2011.

3. Avinashi A, Secker D, Zlotkin S. Buku ajar ilmu gizi. Penerbit Buku Kedokteran. 4th ed.Jakarta.; 2014.p.514,190,223.

4. Palupi E, Sulaeman A, Ploeger A.(2013)

World hunger, malnutrition and brain development of children. Journal on Food, Agriculture and Society ;1:46-56.

5. Georgieff M K. Nutrition and the developing brain: nutrient priorities and measurement. Am J Clin Nutr 2015;85:614S-620S.

6. Solihin RDM, Anwar F, Sukandar D. Kaitan antara status gizi, perkembangan kognitif, dan perkembangan motorik pada anak usia prasekolah. Penelitian Gizi dan Makanan 2013, 36 (1): 62-72.

7. Rahmawati, Fauziyah A, Tanziha I, Hardinsyah, at al, Prevalensi dan Faktor Risiko Kejadian Stunting Remaja Akhir, Jurnal Kesehatan, Vol. 1 No. 2

8. Kemenkes RI, Badan badan Penelitian dan Pengembangan Kesehatan , Laporan Nasional Riskesdas 2018;

9. Stein, A. D., Wang, M., Martorell, R., Norris, S. A., at al (2010). Growth patterns in early childhood and final attained stature: Data from five birth cohorts from low- and middle-income countries. American Journal of Human Biology, 22 (3), 353-359.

10. Onis $M$, et.al. WHO Child Growth Standards. Acta Paediatrica, International Journal of Paediatrics.
2006; Dalam Atmarita, Masalah Anak Pendek di Indonesia dan Implikasinya Terhadap Kemajuan Negara Gizi Indon 2012, 35(2):81-96

11. Robert J, Stein, AD. The Impact of Nutritional Interventions beyond the First 2 Years of Life on Linear Growth: A Systematic Review and Meta-Analysis, Am Nutr 2017;8:(93)23-36.

12. Menko Bidang Pembangunan Manusia dan Kebudayaan, 160 Kabupaten/Kota Prioritas Dengan Masing-masing 10 Desa Untuk Penanganan Stunting (Kerdil), April 2018

13. Soetjiningsih, Ranuh, IG.N.Gde, Tumbuh Kembang Anak, Ed.2, Penerbit Buku Kedokteran EGC,cetakan 2014

14. Reinhardt K, FanzoJ. Addressing chronic malnutrition through multisectoral, sustainable approaches: a review of the causes and consequences. Frontiers in Nutrition and Environmental Sustainability. 2014;1:1-13.

15. Sudiman H. Stunting atau pendek awal perubahan patologis atau adaptasi karena perubahan sosial ekonomi yang berkepanjangan. Media litbang kesehatan, 2008;18:33-43

16. Kemenkes RI, Direktorat Bina Gizi. Standar antropometri penilaian status gizi anak, 2011;p 4-5.

17. Svefors $P$, Rahman $A$, Ekström $A$ C,Khan A.I, Lindström E, Stunted at 10 Years. Linear Growth Trajectories and Stunting from Birth to PreAdolescence in a Rural Bangladeshi Cohort PLOS ONE 2016; 2 .

18. Artaria MD, Perbedaan antara Laki laki dan Perempuan: Penelitian Antropometris pada Anak-Anak Umur 6-19 Tahun, Jurnal Masyarakat Kebudayaan dan Politik Tahun 22, Nomor 4: 343-349 


\section{Media Informasi}

19. Pehlke E. L., Letona P, Hurley K, Gittelsohn J, Guatemalan school food environment: impact on schoolchildren's risk of both undernutrition and overweight/obesity Health Promotion International, 2016;31:542-550

20. Hailegebriel $T$, Undernutrition, intestinal parasitic infection and associated risk factors among selected primary school children in Bahir Dar,Ethiopia BMC Infectious Diseases (2018) 18:394.
21. Tamirat Hailegebriel Undernutrition, intestinal parasitic infection and associated risk factors among selected primary school children in Bahir Dar, Ethiopia, Hailegebriel BMC Infectious Diseases (2018) 18:394.

22. Yasmin, Ghaida; Kustiyah, Lilik; Dwi Riani, Cesilia Meti. Research Article Stunted Children Has Higher Risk of Overweight: A Study on Children Aged 6-12 Years in Eight Provinces in Indonesia. 2019. 